NASA Technical Memorandum 87150

\title{
Fatigue Crack Propagation of Nickel-Base Superalloys at $650^{\circ} \mathrm{C}$
}

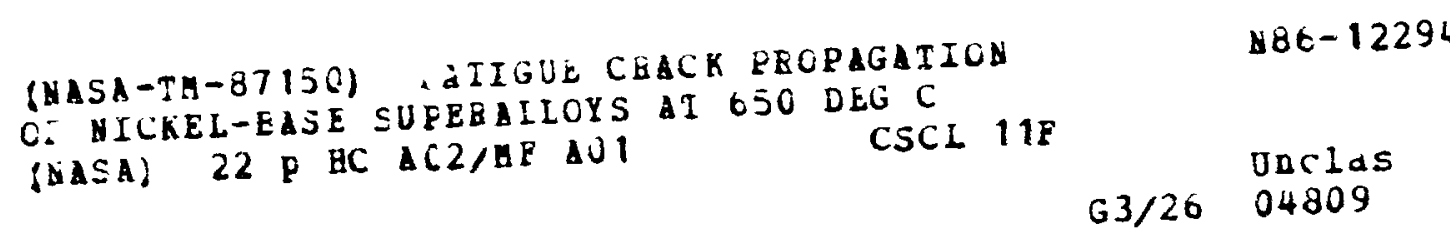

J. Gayóa, T.P. Gabb, and R.V. Miner

Lewis Research Center

Cleveland, Ohic

Prepared for the

Symposium on Low-Cycle Fatigue Directions for the Future sponsored by the American Society for Testing and Materials Bolton Landing, New York, September 30-Octcber 4, 1985

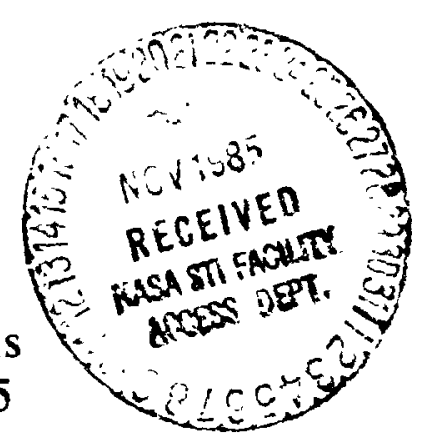




\title{
FATIGUE CRACK PROPAGATION OF NICKEL-BASE SUPERALLOYS AT $650^{\circ} \mathrm{C}$
}

\author{
J. Gayda, T.P. Gabb, and R.V. Miner \\ National Aeronautics and Space Administration \\ Lewis Research Center \\ Cleveland, Ohio 44135
}

\section{SUMMARY}

The $650^{\circ} \mathrm{C}$ fatigue crack propagation behavior of two nickel-base superalloys, René 95 and Waspaloy, were studied with particular emphasis placed on understanding the roles of creep, environment, and two key grain boundary alloying additions, boron and zirconiun. Comparison of air and vacuum data showed the air environment to be detrimental over a wide range of frequencies for both alloys. More in depth analys is on René 95 showed at lower frequencles, such as $0.02 \mathrm{~Hz}$, failure in air occurred by intergranular, environmentally-assisted creep crack growth, while at higher frequencies, up to $5.0 \mathrm{~Hz}$, environmental interactions were still evident but creep effects were minimized. The effect of $B$ and $\mathrm{Zr}$ in Waspaloy was found to be important where environmental and/or creep interactions were present. In those instances, removal of $B$ and $2 r$ dramatica,ly increased crack growth and it is therefore plausible that effective dilution of these elements may explain a previously observed trend in which crack growth rates increased with decreasing grain size.

\section{INTRODUCTION}

Fatigue is usually the life limiting factor in modern aircraft turbine disks. Good resistance to fatigur crack propagation is important as well as resistance to crack initiation, since a crack once present must not propagate to failure between inspection intervals. Previous studies of several nickelbase, $r^{\prime}$ strengthened disk alloys have shown that the advanced, fine grain, high strength alloys possess rel.tively poor fatigue crack propagation resistance at turb!ne disk rim temperatures, particularly when the fatigue cycle includes tensile dwell periods (refs. 1 and 2 ). Since these studies were conducted on comercial alloys rather than a specially designed series of alloys, it was not possible to conclude whether the poor fatigue crack propagation resistance of the advanced alioys was due to their generally finer grain size, higher strength, or possibly lower environmental resistance. More recent studies, in which grain size and strength were systematically varied for single superalloy compositions, have shown that fine grain sice, but not high strength in itself, leads tu accelerated crack growth at $650{ }^{\circ} \mathrm{C}$ (refs. 3 and 4 ). Further, it was snown that the high fatigue crack propagation rates of the fine grain alloys were associated with an intergranular mode of failure even at relatively rapid test frequencies, and that this mode did not occur in the absence of air. In dwell tests, failure was intergranular in both large and fine grain alloys, however, large, grain size still reduced the rate of crack propagation.

To sain a more detalled understanding of the rapid crack growth behavior of the fine grain alloys it is necessary to quantitatively gauge the relative importance of creep, fatigue, and environmental factors in the failure process. This question will be addressed in the first part of the present paper by 
comparing crack growth behavior of René 95, a fine grain, high strength nickelbase superalloy, as a function of test frequency, dwell conditions, and environment.

To address why finer grain superalloys exhibit more rapid fatigue crack propagation, one mechanism relating grain size and grain boundary chemistry to fatigue crack propagation resistance will be assessed. The mechanism to be examined, which is essentially that proposed by Bain and Pelloux for creep crack propagation (ref. 5), is that since decreasing grain size increases grain boundary volume it effectively decreases the concentration of $B$ and $Z r$ at grain boundaries. Both elements are thought to enhance grain boundaries properties in superalloys and their effective dilution may therefore be responsible for the rapid intergranular fatigue crack propagation observed in fine grain superalloys. To test this hypothes is crack propagation tests were run on relatively fine grain Waspaloy with normal and reduced levels of $B$ and $2 r$. The results of these tests and their relation to the fine grain nickel-base superalloys will be discussed in the second part of the present paper.

\section{MATERIALS AND PROCEOURES}

Creep-fatigue-environment study. - Crack growth tests designeo to study the effects of creep, fatigue, and environmental interactions were conducted on a single nickel-base superalloy of current interest to the aerospace community, Rene 95. This alloy is typical of the current generation of fine grain, high strength nickel-base superalloys used as disk materials in the hot section of aircraft turbine engines. It is strengthened by the ordered intermetallic $\gamma^{\prime}$ phase and is produced by powder metallurgy technology.

Argon atomized powder having the composition listed in table I was used in the present study. This powder was hot isostatically pressed (HIP) at $1120^{\circ} \mathrm{C}$ and $105 \mathrm{MPa}$ for $3 \mathrm{hr}$ producing essentially 100 percent density. The product was subsequently solution treated at $1120^{\circ} \mathrm{C}$ for $1 \mathrm{hr}$, air cooled, and aged at $760{ }^{\circ} \mathrm{C}$ for $8 \mathrm{hr}$. The resulting microstructure has an average grain size of 8 um and contains about 50 vol $*$ of $\gamma^{\prime}$ precipitates about 0.1 um in diameter plus a small amount of the MC cartide. Tensile properties for the René 95 studied are presented in table I and are typical of HIP René 95.

All crack growth data were generated using the compact tension specimen shown in figure 1 which was madified to maximize material usage. Both cyclic (R-ratio of 0.05 ) and static crack growth tests were run at $650^{\circ} \mathrm{C}$ under load control using a closed loop servohydraulic test system equipped with an electric resistance furnace in a chamber which may be evacuated by a diffusion

pump. Vacuum tests were run at a pressure between $1 \times 10^{-5}$ and $1 \times 10^{-6}$ torr. Al? other tests were run in laboratory air.

All compact tension specimens were precracked at room temperature in laboratory air at $20 \mathrm{~Hz}$. A symmetric, triangular waveform was used for the cyclic crack growth tests, which were run at frequencies of $0.02,0.33$, and $5 \mathrm{~Hz}$. Tests with a $120 \mathrm{sec}$ dwell period at maximum load, but otherwise the same as the $0.33 \mathrm{~Hz}$ tests, were run to accentuate creep interactions. For the cyclic crack propagation tests, crack growth rates per cycle, da/dn, were monitored with a dc potential drop system described elsewhere (ref. 3) and were correlated with the stress intensity range, $\Delta K$. For the static crack propagation tests, crack growth rates/time, da/dt, were also monitored with a dc potential 
drop system and rere correlated with the stress intensity factor, $K$. The $K$ calibration curve for the modified specimen geometry was calculated using a boundary collocation scheme developed by Newman (ref. 6). At least two crack growth tests were run for every condition investigated herein.

Grain boundary chemistry study. - The effect of grain boundary chemistry on crack propagation rates was studied in a second nickel-base superalloy, Haspaloy. The use of HIP Rene 95 in this experiment was prohibited by the cost and time required to produce nonstandard compositions by powder metallurgy. However, the alloy chosen, Haspaloy could be produced with the available facilities by casting ingots of compositions desired and extruding them to obtain a fine grain microstructure.

Haspaloy is an older generation nickel-base superalloy with lower strength than René 95 primarily due to its lower $y^{\prime}$ content. Nevertheless, work by Lawless (ref. 7) on Waspaloy and Gayda, Miner, and 6abb (ref. 4) on several nickel-base superalloys has shown that finer grain sizes tend to promote rapid, ntergranular crack growth. Thus it was felt that the behavior of Waspaloy is -epresentative of this class of superalloys and that Haspaloy was a suitable vehicle for studying the effects of grain boundary chemistry on crack growth tishavior.

After several casting iteratior.s, ingots with "nomal" and low levels of 8 and $\mathrm{Zr}$ were obtained having otherwise nearly identical compositions as shown in table II. To refine the as-cast structure, these ingots were extruded at $1060{ }^{\circ} \mathrm{C}$ using a $6: 1$ reduction ratio. The extrusions were then soiutioned at $1010^{\circ} \mathrm{C}$ for $2 \mathrm{hr}$, forced air cooled, and then given a two step aging treatment of $845^{\circ} \mathrm{C}$ for $4 \mathrm{hr}$ and $760^{\circ} \mathrm{C}$ for $16 \mathrm{hr}$. This heat treatment is similar to that used for commercial disk applications except the solution temperature was lowered slightly to prevent grain growth. The resulting microstructures for both compositions are shown in figure 2. The grain sizes are both about $40 \mathrm{~mm}$. Both alloys were found to contain approximately 25 vol $\times \gamma^{\prime}$ and a small amuunt of the $\mathrm{MC}$ and $\mathrm{M}_{23} \mathrm{C}_{6}$ carbides. The "normal" composition alsu contains a small amount of the $\mathrm{M}_{3} \mathrm{~B}_{2}$ boride.

Crack growth tests were run on modified compact tension specimens previously described. Test temperature and procedures were identical to that already described for René 95 . Cyclic crack propagation tests were run in air and vacuum at a frequency of $0.33 \mathrm{~Hz}$ with and without a $120 \mathrm{sec}$ dwe 11 at maximum load. The specimens were oriented so as to produce fracture perpendicular to the extrusion direction. The axes of tensile and creep specimens were also oriented to fracture in this plane.

\section{RESULTS ANO DISCUSSION}

Creep-fatigue-environment study. - Fatigue crack growth data for the fine grain nickel-base superalloy René 95 are plotted in figures 3 and 4 for tests in air and vacuum, respectively. As seen in figure 3, crack growth rates in air varied by about one order of magnitude over the range of frequencies investigated. As expected, crack growth rates increased as test frequency decreases and increased dramatically for the $120 \mathrm{sec}$ dweil test. In vacuum, figure 3 , the crack growth rates showed a much smaller variation with frequency and the $120 \mathrm{sec}$ dwell test is seen to be less damaging. especially at lower values of $\Delta K$. Comparing tests of the same frequency in air and vacuum, crack growth 
rates were clearly higher in air. This effect is seen to be most pronounced in the lower frequency tests. The increase of the crack growth rate in air was about a factor of two for the $5 \mathrm{~Hz}$ tests, but 50 times for the $120 \mathrm{sec}$ dwell tests.

Creep crack growth rates for Rene 95 are presented in figure 5 for both air and vacuum. It may be seen that air enhanced the rate of creep crack jrowth almost thousand fold at this ti nperature. Further, crack growth rates in the two environments showed the greatest difference at lower values of $k$. Cyclic crack growth rates for the $120 \mathrm{sec}$ dwell test in air and vacuum also differed most at low $\Delta K$.

To analyse the effects of creep, fatigue, and environment in a more quantitative fashion the following scheme was adopted. First, the crack growth data at $5 \mathrm{~Hz}$ in vacuum was taken as the approximate rate of fatigue crack growth unaffected by creep or the air environment, $(\mathrm{da} / \mathrm{dn})_{\mathrm{f}}$. The validity of this assumption is supported by the near collapse of the fatigue crack growth data in vacuum at 5 and $0.33 \mathrm{~Hz}$. This "pure" fatigue crack growth rate was then combined with the creep crack growth rate measured in air, da/dt, using a time iniagration method similar to that proposed by Saxena (ref. 8) to predict fatigue crack growth rates in air. The general form of this equation is shown below:

$$
d a / d n=(d a / d n)_{f}+\int(d a / d t) d t
$$

The above expression is then evaluated at a given value of $\Delta K$.

The first term in equation (1) was approximated by the Paris expression:

$$
(d a / d n)_{f}=B \Delta K^{m}=1.07 \times 10^{-11} \Delta K^{2.95}
$$

The integral in equation ( 1 ) was evaluated over one cycle from $t_{1}=0$ to $t_{2}=(1 / N)+t_{h o l d}$, where $v$ is the frequency of the test and thold is the duration of any dwell.

Before tho integral can be evaluated an expression for da/dt must be formulated. In this case the following expression was adopted:

$$
\mathrm{da} / \mathrm{dt}=A k^{n}=1.37 \times 10^{-16} \mathrm{~K}^{6.2}
$$

This is merely a convenient form which accurately represents the creep crack growth data in air.

To perform the integration, an expression for $k$ as a function of time within the cycle was then written based on the waveform in question, in this instance, a symmetric, triangular waveform with an optional dwell period at maximum load. The form of this expression and the mechanics of the integration are described in the appendix. The final relation is shown below:

$$
d a / d n=B \Delta K^{m}+A \Delta K^{n}\left[Z /(v(n+1))+t_{h o l d} /(1-R)^{n}\right]
$$

where

$$
Z=\left(1-R^{n+1}\right) /(1-R)^{n+1}
$$


Evaluating the above expression at various values of $\Delta K$ for the 5 , 0.33 , and $0.02 \mathrm{~Hz}$ tests as well as the $120 \mathrm{sec}$ dwell test yielded the plots shown in figure 6 . Also shown for comparative purposes is the $5 \mathrm{~Hz}$ vacuum data used to approximate the "pure" fatigue crack growth rates.

Before proceeding. two points should be made about the time integration scheme used herein. First, the effect of creep crack growth is overestimated at low $\Delta K$ since the expression for the creep crack growth rate in air, equation (3), does not reflect the sharp decrease in da/dt below $K=20 \mathrm{MPa}$ $\sqrt{7}$ shown in figure 5 . The effect is, however, relatively small on predicted fatigue crack growth rates at or above $\Delta K=25 \mathrm{MPa} \sqrt{16}$, as the majority of the creep component in a fatigue cycle is incurred near $k_{\max }$ with the waveforms used in this study. Second, the time integration scheme as applied here in simply adds the creep component as measured in air to the "pure" fatigue component. The effects of environment are ignored except as they effect creep crack growth. Any interactive effects between the air environment and fatigue loading are not considered.

Examiration of the predicted fatigue crack growth rates in air, figure 6 , shows that simple addition of the air creep crack growth rates to the "pure" fatigue crack growth rate dces not adequately explain the deleterious effect of the air environment at 5 and $0.33 \mathrm{~Hz}$. At these higher frequencies the predicted crack growth rates are only slightly greater than the "pure" fatigue crack growth rates, especially at low $\Delta K$. This suggests that there is an additional environmental effect in these fatigue tests which is not present in the creep crack growth tests run in air. Figure 7 shows that the $0.33 \mathrm{~Hz}$ tests exhibited an intergranular mode of failure indicating some form of environmental and/or creep damage is occurring, however the mode of failure was predominantly transgranular in the $5 \mathrm{~Hz}$ air tests with only a limited amount of intergranular failure evident.

While simple addition of the air creep crack growth rate to th- "pure" fatigue crack growth rate underpredicts fatigue crack growth for tlic higher frequency tests it does much better for the cycles with a larger creep component, the $0.02 \mathrm{~Hz}$ and $120 \mathrm{sec}$ dwell +..sts, shown in figure 6 . In these tests it would appear that any acceleration in crack growth due to additional environmental interactions seen at higher frequencies is largely masked by the high crack growth rates produced by the large amount of creep crack growth in air. For example, the crack growth rate in air for the $120 \mathrm{sec}$ dwell test is over two orders of magnitude greater than the "pure" fatigue crack growth rate Jue to the large amount of creep crack growth per cycle.

The effect of air on the high crack growth rates of the $0.02 \mathrm{~Hz}$ and $120 \mathrm{sec}$ dwell tests in air is by no means minimal. This was. demonstrated by the extremely low crack growth rates for the $120 \mathrm{sec}$ dwell test in vacuum relative to that in air. Further tise fracture modes of the air and vacuum $120 \mathrm{sec}$ dwell tests were clearly different as seen in figure 7, that in air being decidedly more intergranular.

On the basis of these observations it appears that several failure mechanisms are operative in air run over the range of frequencies studied. At relatively high frequencies represented by the tests at $5 \mathrm{~Hz}$, it is probable that the rate of crack growth outpaces the rate of oxygen penetration along grain boundaries, as evidenced by the transgranular fracture mode. Here the mild effect of air is probably related to environmental effects at or very 
near the crack tip. These could include penetration and embrittlement by oxygen ahead of the crack tip at slip bands or oxidation of newly formed cra:k surfaces that would inhibit "rewelding."

At intermediate frequencies, represented by the tests at $0.33 \mathrm{~Hz}$, the rate of oxygen penetration along grain boundaries is probably significant compared with the rate of crack propagation, as indicated by the more rapid, intergranular failure mode in air. Here the crack is propagating along grain boundaries apparently affected by air. It is possible that the grain boundaries have been embrittled by the actual depletion of oxide forming elements as proposed by Gell and Leverant (ref. 9), or more likely at this test temperature, just by the presence of oxygen diffused into the grain boundaries ahead of the crack tip.

At still lower frequencies, represented by the $0.02 \mathrm{~Hz}$ and the $120 \mathrm{sec}$ dwell tests, the rate of oxygen penetration along grain boundaries must again be significant compared to the rate of crack propagation. However, there appears to be sufficient time in these cycles that the mechanism of crack growth resembles that occurring during static creep in an air environment as evidenced by the success in predicting crack growth rates at lower frequencies. Under these conditions oxygen may weaken or embrittle grain boundaries as previously descrihed, or it may also increase creep rates, and therefore crack growth rates by altering cavitation kinetics as proposed by McLean (ref. 10).

Regardless of the mechanisms involved it is apparent that for René 95 fatigue crack growth rates for cycles with a substantial creep component are controlled by intergranular, environmentally assisted creep crack growth; while at higher frequencies fatigue crack growth rates are enhanced by the presence of the air environment with minimal creep interactions.

Grain boundary chemistry study. - Before examining the effects of B arid $2 r$ on crack growth in Waspaloy, a short discussion of tensile and creep properties is in order. As seen in table II, the $650^{\circ} \mathrm{C}$ yield and ultimate tensile strengths were virtually unaffected by lowering $B$ and $\mathrm{Zr}$ concentrations. The tensile elongation of the low $B$ and $2 r$ alloy was diminished but still acceptable at 12 percent, compared with 28 percent for the "normal" Waspaloy. The strength levels of both alloys were comparable to commercial Waspaluy as is the ductility of the "normal" alloy. The creep properties of the low B and $\mathrm{Zr}$ alloy, both rupture life and ductility, were also degraded as anticipated, figure 8.

The crack growth behavior in air and vacuum at $0.33 \mathrm{~Hz}$ for both alloys is shown in figure 9. Lowering the $B$ and $\mathrm{Zr}$ level led to a threefold increase in crack growth rates in air. There wes also a corresponding transition in fracture appearance to a more intergranular mode with lowered $B$ and $\mathrm{Zr}$ levels, as seen in figure 10. In vacuum the crack growth rate: of both alloys were nearly equivalent and less than that of either alloy in air. In addition, both alloys had a transgranular fracture appearance in vacuum, diso shown in figure 10.

The crack growth behavior in air and vacuum for the $120 \mathrm{sec}$ dwell test for both alloys are plotted in figure 11 . In air the low $B$ and $\mathrm{Zr}$ alloy had a crack growth rate morn than one order of magnitude greater than the "normal" alloy. For both alloy the crack growth rate was greater than that observed at $0.33 \mathrm{~Hz}$, although the effect in the low $B$ and $\mathrm{Zr}$ alioj was much greater. For both alloys the mode of crack growth for the $120 \mathrm{sec}$ dwell test in air was 
predominantly intergranular. As in the $0.33 \mathrm{~Hz}$ tests, the crack growth rates of both alloys were supressed in vacuum, but the crack growth rate of the alloy with lower $B$ and $2 r$ levels remained quite high, well above that obtained in air for the alloy with higher levels of $B$ and $2 r$. Fracture in the low $B$ and $2 r$ alloy was predominantly intergranular for the vacuum dwell tests, however, that of the "normal" alloy was mixed as seen in figure 10.

These results clearly show that removing $B$ and $Z r$ adversely effects the crack growth behavior of Haspaloy when environmental and creep components are present alone or in combination. However, these two alloy addition have little effect on the "pure" fatigue crack growth process where failure is predominantly transgranular.

Comparison of alloy beiaviors. - The effects of air and tensile dwell on the crack growth behaviors of René 95 , and the two Waspaloy compositions are compared schematically in figure 12 . The crack growth rates at $\Delta K=30 \mathrm{MPa}$ $\sqrt{11}$ for the $0.33 \mathrm{~Hz}$ and $120 \mathrm{sec}$ dwell tests in both vacuum and air are plotted vertically at the four corners of the three-dimensional plot. The $0.33 \mathrm{~Hz}$ tests are the highest frequency tests conducted on all three alloys in vacuum and are taken as the "pure" fatigue crack growth behavior in this comparison.

It may be seen that the three alloys exhibit differing effects of air and dwell individually or in combination. However, the "pure" fatigue behavior of the thuze alloys is very similar and as previously stated removing $B$ and $Z r$ has little effect on crack growth behavior in this regime.

In vacuum, both René 95 and "normal" Waspaloy showed essentially no effect of the $120 \mathrm{sec}$ tensiie dwell. In the absense of air, creep loads have minimal effect on the crack growth behavior of these two alloys. However, Waspaloy with low $B$ and $2 r$ exhibited a more than tenfold increase in crack growth rates une to the application of the $120 \mathrm{sec}$ dwell in vacuum, reflecting its low creep strength and ductility.

In air, al! three alloys showed an increase in crack growth rates for both test cycles. However, the increase in - rack growth rates was larger for René 95 and the Waspaloy with low B and 2 ? i an for "normal" Waspaloy, particularly for the $120 \mathrm{sec}$ dwell test. Low $B$ and $\mathrm{Zr}$ levels were clearly detrimental to Waspaloy in both test cycles. This is unlike the findings of floreen and Davidson (ref. 11) on the Ni-Fe-base superalloy they studied, NIMONIC PE16. It may be that PE 16 is not as environmentally sensitive as the general class of $\mathrm{Ni}$-base superalloys with higher fractions of $\mathbf{Y}^{\prime}$.

As the behavior of Waspaloy with low $B$ and $2 r$ somewhat mimics that of the fine grain René 95, support is given to a mechanism relating effective grain boundary composition to crack growth resistance such as that proposed by Bain and Pelloux (ref. 5). The effect of decreasing grain size in increasing fatigue and creep-fatigue crack growth rates of superalloys in air (refs. 2 and 3) may result, at least partily, from an effective dilution of the $B$ and $\mathrm{Zr}$ concentration at grain boundaries.

St111, the effect of environment on René 95 is even more severe than that on Waspaloy with low $B$ and $2 r$ under creep-fatigue conditions. The high crack growth rates for Waspaloy with 1 . I B and $\mathrm{Zr}$ in the $120 \mathrm{sec}$ dwell test in air appears to be as much due to basically poor creep behavior as to environmental 
sensitivity. For Rene 95 the $120 \mathrm{sec}$ dwell had no effect except in tests conducted in air. Thus, other factors, such as generally lower cr concentration, probably also contribute to the enhanced crack growth rates of the advanced, fine grain superalloys like René 95 when creep, fatigue, and environment interactions are prevalent.

\section{CONCLUSIONS}

The results of this and previous studies show that rapid i.itergranular crack propagation observed in high strength, fine grain Ni-base superalloys, such as René 95, are a result of a strong environmental interaction. For low frequencies or cycles incorporating a tensile dwell, the damage mechanism is similar to that found in creep crack growth in air. Yet even for high frequency tests where creep interactions are minimal, the damaging effect of air is quite large. It has been shown previously that such environmental sinsitivity is accentuated by fine grain microstructures. The present results on thr effects of $B$ and $Z r$ concentrations in Waspaloy support the concept that a significant portion of the effect of fine grain size may be explained by the effective dilution of 8 and $\mathrm{Zr}$ concentration at grain boundaries due to an increase in grain boundary volume. 


\section{APPENDIX}

To evaluate the creep component of crack growth, the integral is broken into three parts, the ramp up, the hold, and the ramp down, as shown below:

$$
\int(d a / d a) d t=\int_{0}^{l / 2 v} A K^{n} d t+A K_{\max } t_{h o l d}+\int_{1 / 2 v}^{1 / v} A K^{n} d t^{n}
$$

Since the first and the third term are numerically equivalent they may be combined as follows:

$$
=2 \int_{0}^{1 / 2 v} A K^{n} d t+A K_{\max } t_{h o l d}
$$

$K$ is a linear function of time, $t$, as shown below:

$$
K=2 v \Delta K t+K_{\min }
$$

Substituting this expression for $K$ in the integral one obtains:

$$
=2 \int_{0}^{1 / 2 v} A\left(2 v \Delta K t+K_{\min }\right)^{n} d t+A K_{\max } t_{\text {hold }}
$$

Expressing $K_{\min }$ and $K_{\max }$ in terms of $\Delta K$ and $R$, the load ratio, the following expression is obtained:

$$
=2 \int_{0}^{l-2 y} A(2 v \Delta K t+(R \Delta K) /(1-R))^{n} d t+\left(A \Delta K^{n} t_{h o l d}\right) /(1-R)^{n}
$$

The results of the integration are shown below:

$$
\begin{gathered}
=\left(\left(A \Delta k^{n}\right) /(v n+n)\right)\left[(2 v t+R /(1-R))^{n+1}\right]^{t=1 / 2 v} \\
+\left(A \Delta k^{n} t_{h o l d}\right) /(1-R)^{n} t=0
\end{gathered}
$$

Note that $\Delta K$ is constant for a given cycle and has been removed from the intergrand as $\Delta K^{n}$. Evaluating the limits yields the following expression:

$$
\begin{gathered}
=\left[\left(\Delta \Delta K^{n}\right) /(v n+n)\right]\left[(1+Q)^{n+1}-Q^{n+1}\right] \\
+\left(A \Delta K^{n} t_{h o l d}\right) /(1-R)^{n}
\end{gathered}
$$

where

$$
Q=R /(1-R)
$$

This can be simplified by combining like terms to yield the second term of equation (4) in the text: 
$=A \Delta K^{n}\left[Z /(v(n+1))+t_{h o l d} /(1-R)^{n}\right]$

where

$$
Z=\left(1-R^{n+1}\right) /(1-R)^{n+1}
$$




\section{REFERENCES}

1. Cowles, B.A., Sims, D.L., Warren, J.R., and Miner, R.V., Journal of Engineering Materials Technology, Vol. 102, No. 4, Oct. 1980, pp. 356-363.

2. Cowles, B.A., and Warren, J.R., "Evaluation of the Cyclic Behavior of Aircraft Turbine Disk Alloys," NASA CR-165123, National Aeronautic: and Space Administration, Washington, O.C., Aug. 1980.

3. Gayda, $\therefore$, and Miner R.V., Metallurgical Transactions A, Vol. 14A, No. 11, Nov. 1983, pp. 2301-2308.

4. Gayda, J., Miner, R.V., Gabb, T.P., in Superalloys 1984, M Fiell, ed., The Metallurgical Society of the AIME, Warrendale, $\mathrm{PA}_{4} 19 R_{4}, \mathrm{DP} .731-740$.

5. Bain, K.R., and Pelloux, R.M., in Superalloys 1984, Y. Ge?., ed., The Metallurgical Society of AIME, Warrendale, PA, 1984, DD. $38,-i: 5$,

6. Newman, J.C., in Fracture Analysis, ASTM STP-560. ASTM, Philadelfitia, PA, 1974, Pp. 105-121.

7. Lawless, B.H., "Correlation Between Cyclic Load Rejponse and Fatigue Crack Propagation Mechanisms in the Ni-Base Superal loy Waspaloy," Masters Thesis, University of Cinrinnati, Cincinnati, $\mathrm{OH}, 1980$.

8. Saxsena, A., Fatigue of Engineering Matertals and Structures, Vol. 3, No. 3, 1980, Pp. 247-255.

9. Gel1, M. and Leverant, G.R., in Fatigue at Elevated Temperatures, A.E. Garden, A.J. MCEvily and C.H. Wells, eds., ASTM SPT-520, ASTM, Philadelphia, PA, 1973, pp. 37-67.

10. McLean, D., Metals Forum, Vo1. 1, No. 1-2, 1981, pp. 44-47.

11. Floreen, S., and Davidson, J.M., Metallurgical Transactions A, Vol. 14A, No. 5, May 1983. pp. 895-901. 
TABLE I. . COMPOSIITON AND $650{ }^{\circ} \mathrm{C}$ TENSILE PROPFRTIES OF RENÉ 95

\begin{tabular}{|c|c|ll|}
\hline Element & Weight percent & \multicolumn{2}{|c|}{ Tensile properties } \\
\hline $\mathrm{Cr}$ & 13.0 & 0.2 percent yield & $1070 \mathrm{MPa}$ \\
$\mathrm{Co}$ & 8.2 & Uitimate & $1410 \mathrm{MPa}$ \\
Mo & 3.3 & Elongation & 13 percent \\
W & 4.3 & & \\
$\mathrm{Nb}$ & 3.6 & & \\
$\mathrm{Ti}$ & 2.0 & & \\
$\mathrm{Al}$ & 3.7 & & \\
$\mathrm{C}$ & 0.047 & & \\
$\mathrm{~B}$ & $0 . \mathrm{J} 22$ & \\
$\mathrm{Zr}$ & 0.025 & \\
$\mathrm{Ni}$ & $\mathrm{Balance}$ & \\
\hline
\end{tabular}


TABLE II. - COMPOSITION IN WT\% AND $650^{\circ} \mathrm{C}$ TENSILE PROPERTIES OF THE TWO WASPALOY EXTRUSIONS

\begin{tabular}{|c|c|c|c|c|c|c|}
\hline Element & Low $B+2 r$ alloy & "Norma.1" alloy & Material & $\begin{array}{l}\text { Yield } \\
0.2 \text { percent, } \\
\mathrm{MPa}\end{array}$ & $\begin{array}{c}\text { Ultimate, } \\
M P_{\bar{a}}\end{array}$ & $\begin{array}{c}\text { Elongation, } \\
\text { percent }\end{array}$ \\
\hline $\begin{array}{l}\mathrm{Cr} \\
\mathrm{Co} \\
\mathrm{Mo} \\
\mathrm{Ti} \\
\mathrm{Al} \\
\mathrm{C} \\
\mathrm{B} \\
\mathrm{Zr} \\
\mathrm{Ni}\end{array}$ & $\begin{array}{c}20.8 \\
12.8 \\
4.58 \\
3.53 \\
1.81 \\
0.045 \\
0.001 \\
0.001 \\
\text { Balance }\end{array}$ & $\begin{array}{c}20.7 \\
12.8 \\
4.48 \\
3.55 \\
1.79 \\
0.013 \\
0.025 \\
0.053 \\
\text { Balance }\end{array}$ & $\begin{array}{l}\text { Low B }+\mathrm{Zr} \\
\text { "Normal" alloy }\end{array}$ & $\begin{array}{l}810 \\
770\end{array}$ & $\begin{array}{l}\text { lúisG } \\
1090\end{array}$ & $\begin{array}{l}12 \\
28\end{array}$ \\
\hline
\end{tabular}




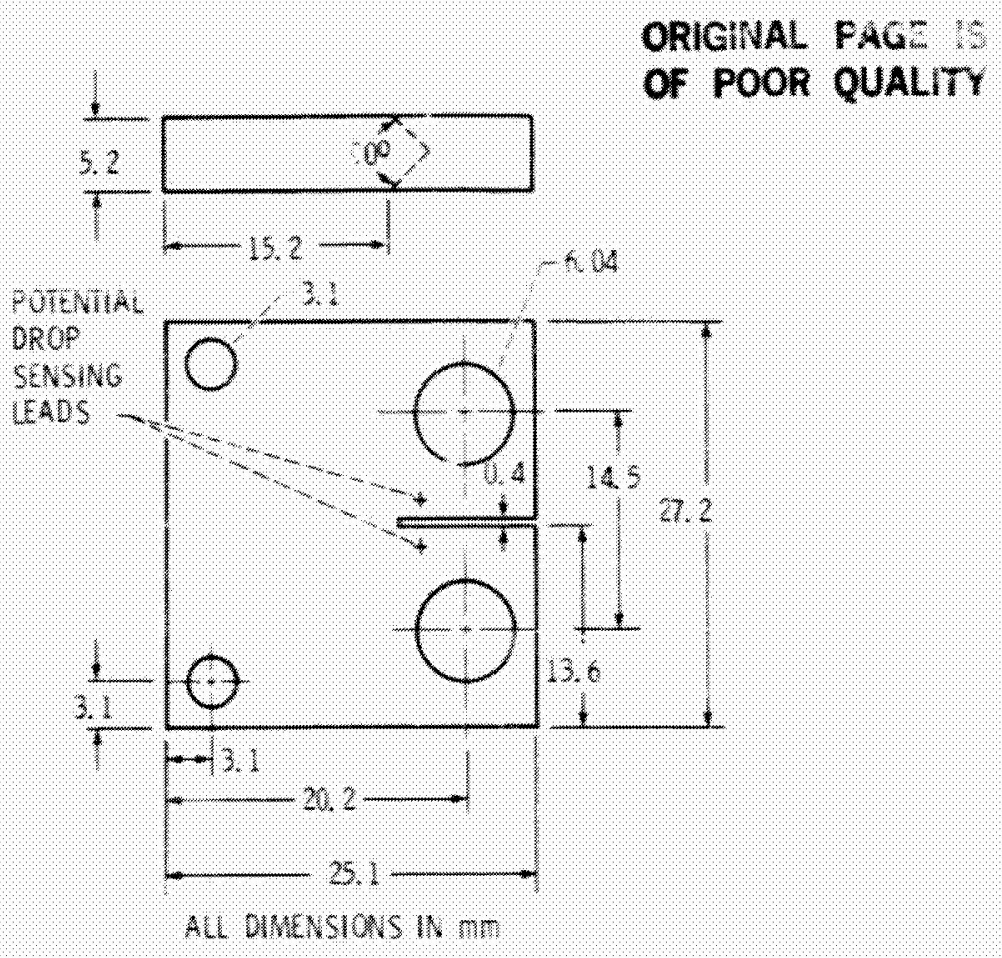

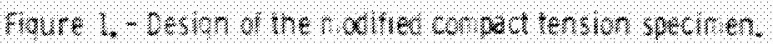
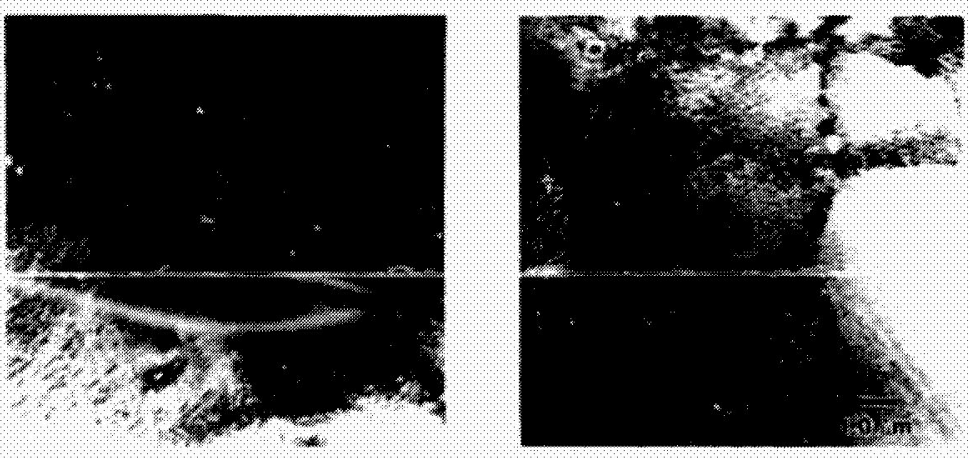

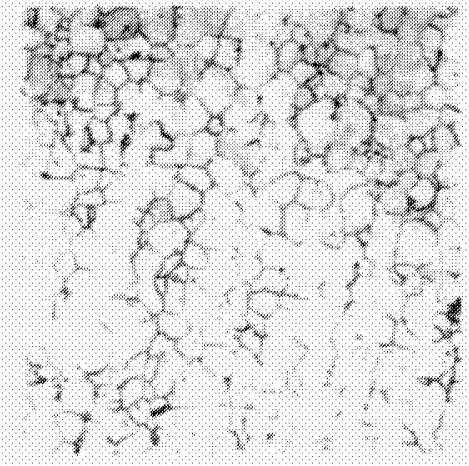

Nornat Wasplut

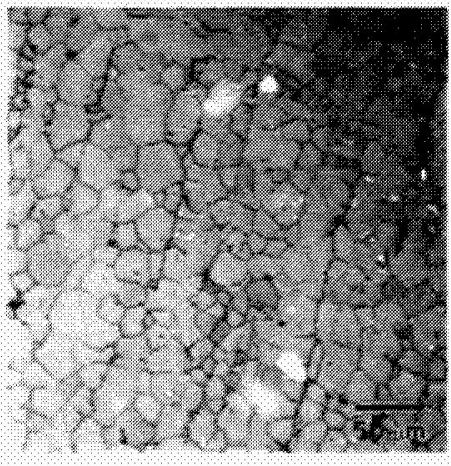

lw 8 and $2 R$ Waspaloy

Figure 2 - Nicrostudures of the two Waspalov compositions 


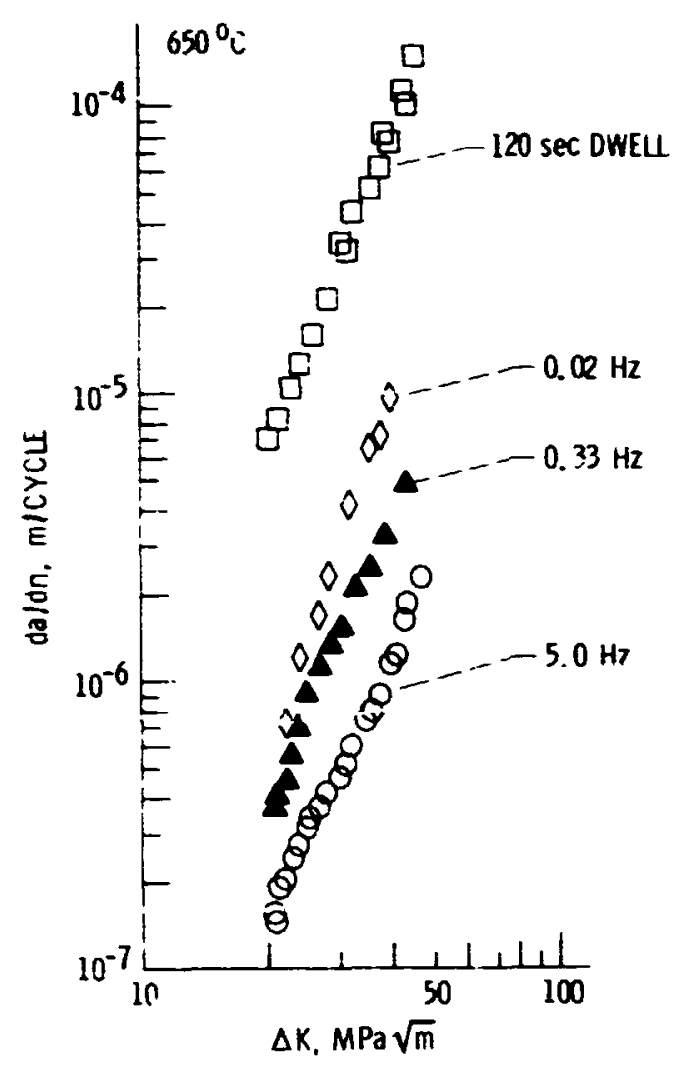

Figure 3. - Fatigue crad growth rates of René 95 tested in air.
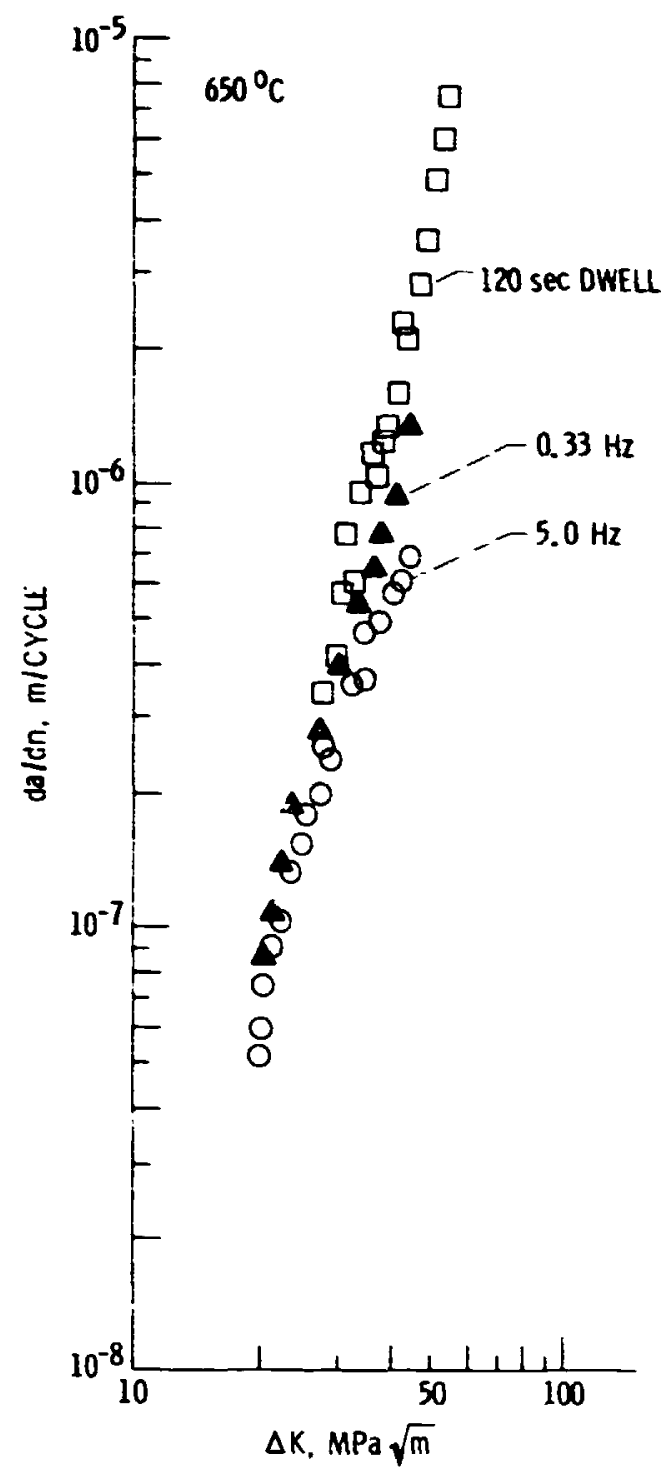

Figura 4 - Fatigue crack gianth rates of René 95 tested in vacium. 


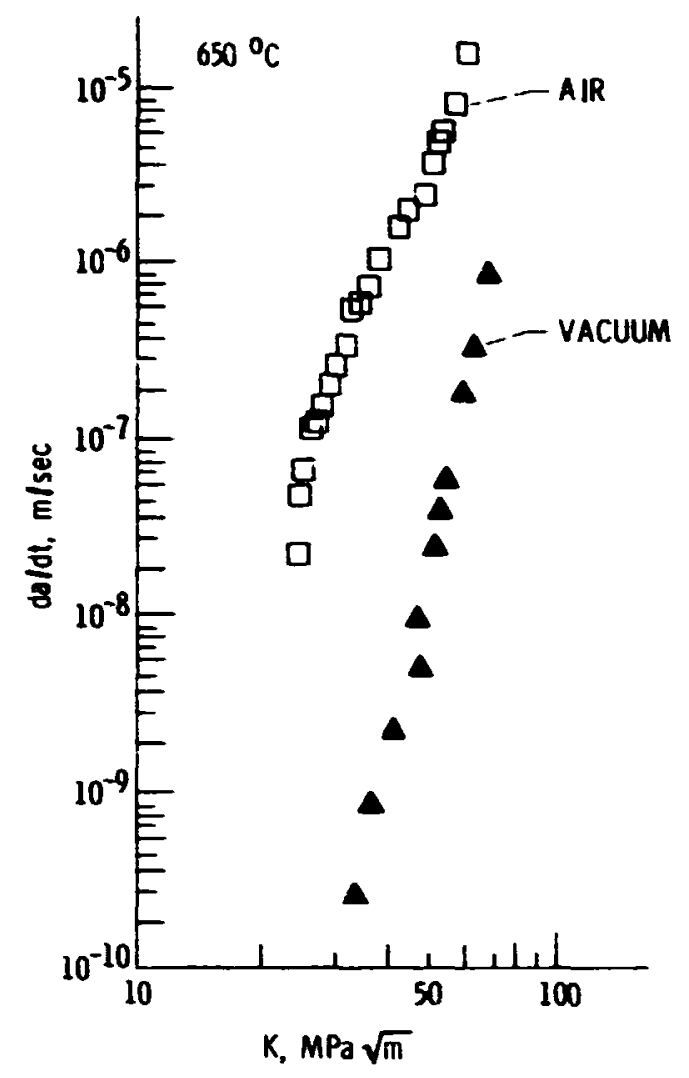

Figure 5. - Creek crack grourth rates of René 95 in air and vacuum.

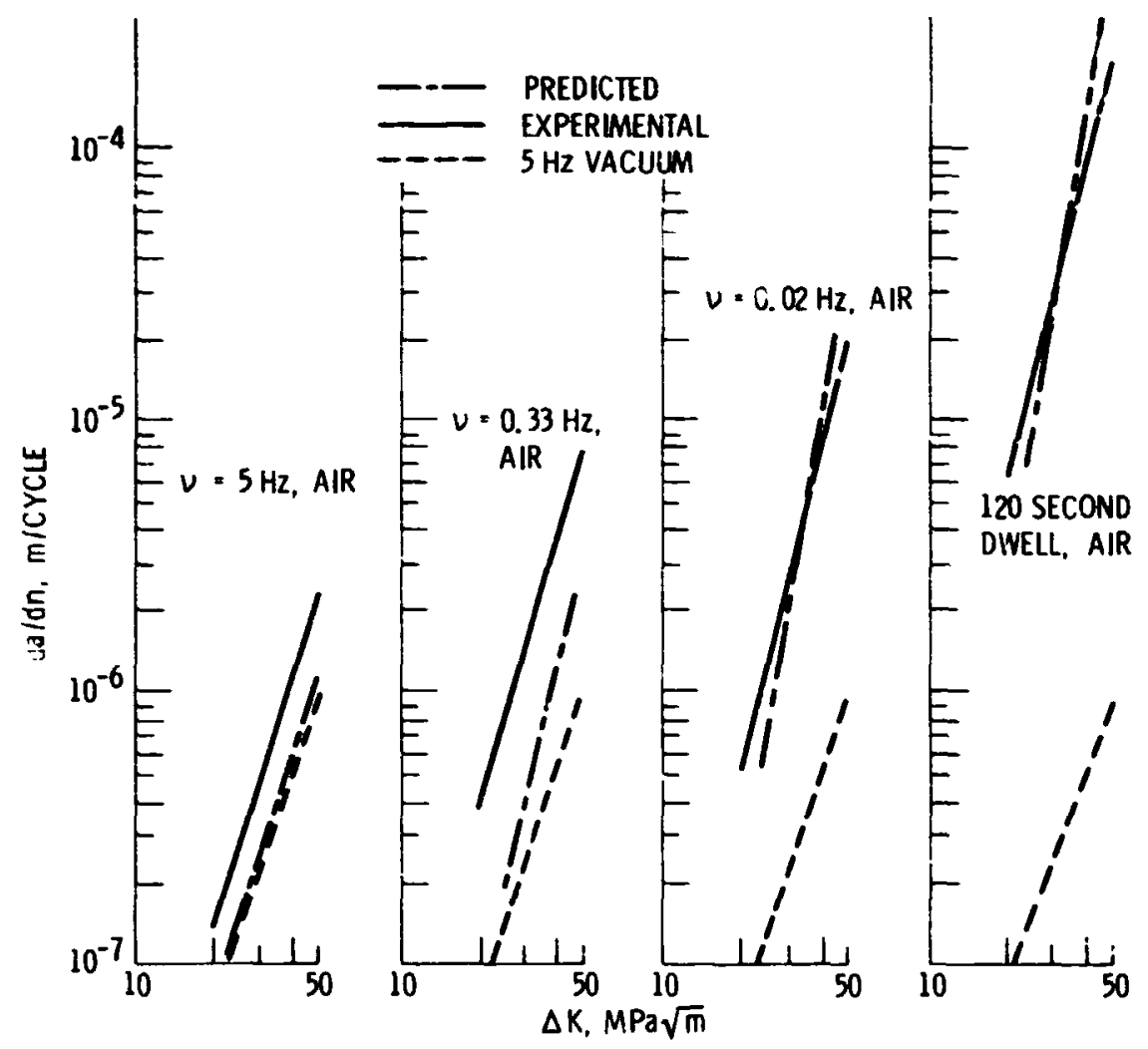

Figure 6. - A comparison of predicted and observed crack growth rates of René 95 at $650{ }^{\circ} \mathrm{C}$ 


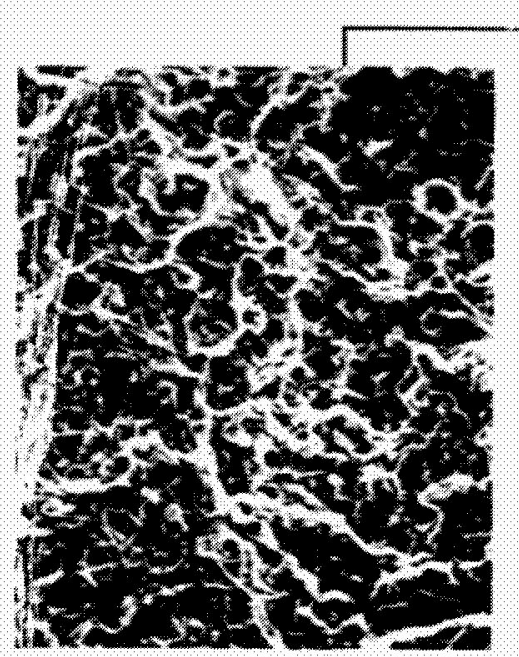

Dwell

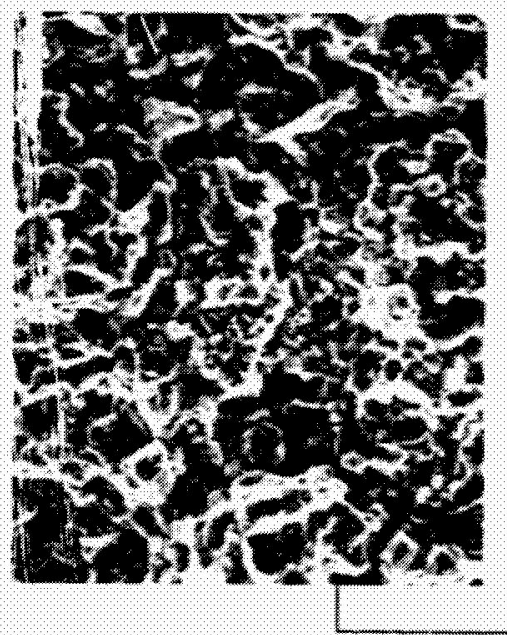

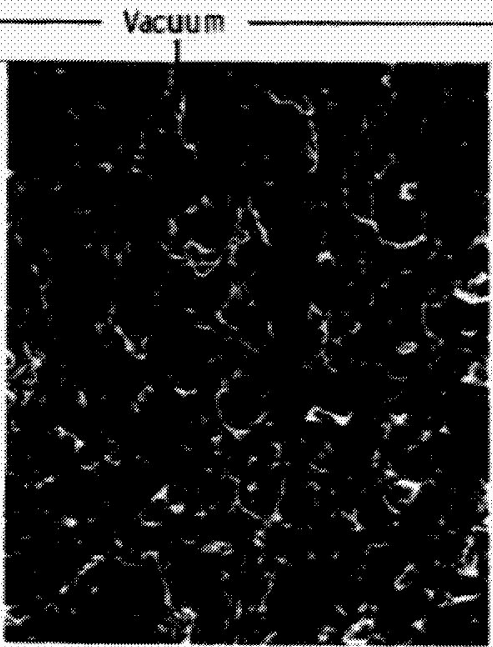

$0,33 \mathrm{kz}$
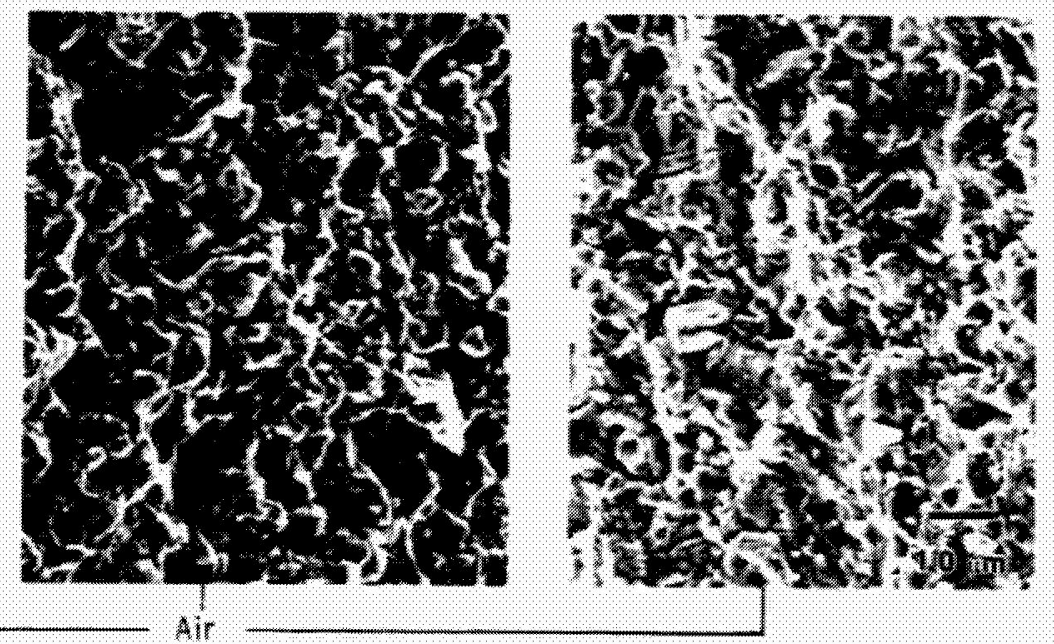

Fiqure 7. - Fracture nodes observed in Rene 95 crack growh lests at $650^{\circ} \mathrm{C}$.

ORIGINAL PAGE IS OF POOR QUALITY

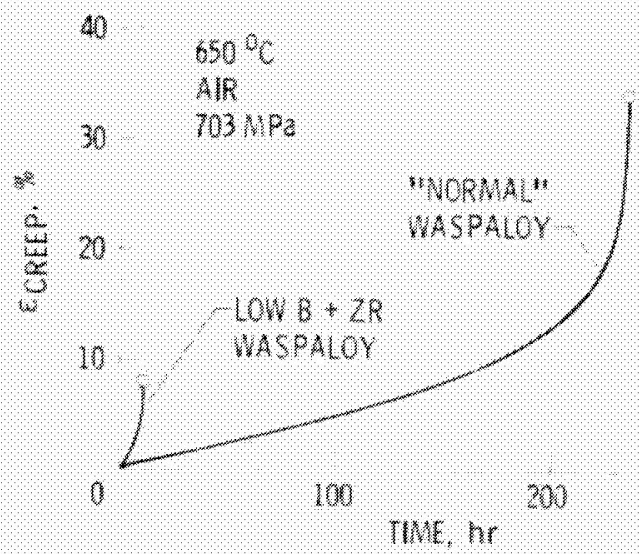

300

Frore a-cree curves of the two waspalsy com: whrtwons. 


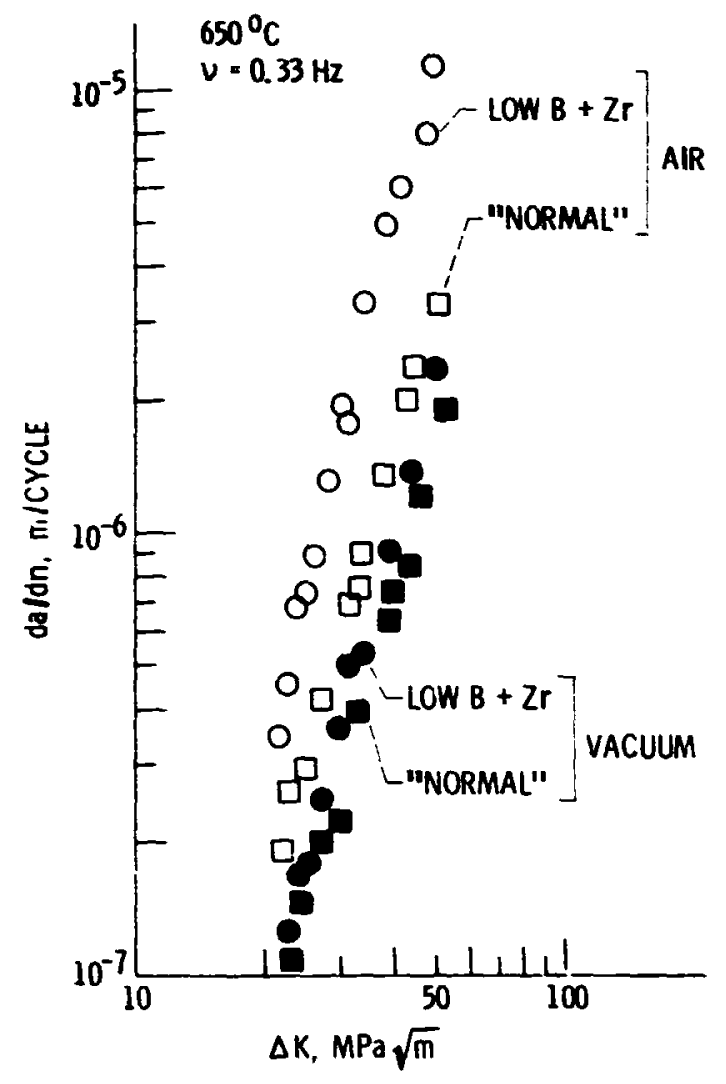

Figure 9. - Fatigue crack growth rates of the two Waspaloy compositions. 


\section{ORIGINAL PAGE IS
OF POOR QUALITY}

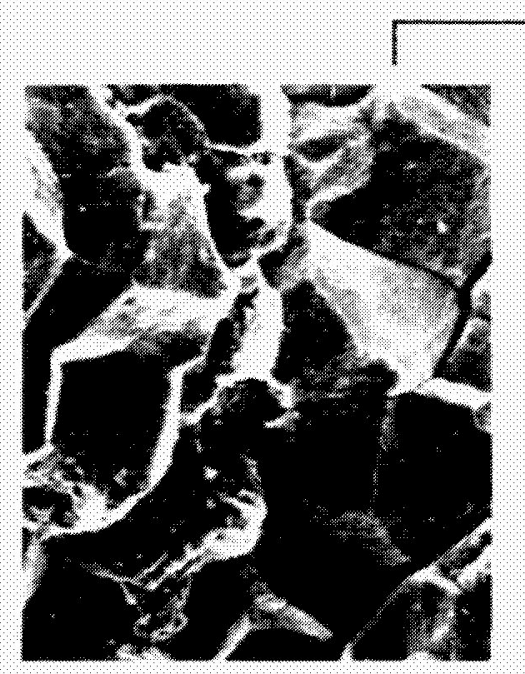

Dwellin wacum.

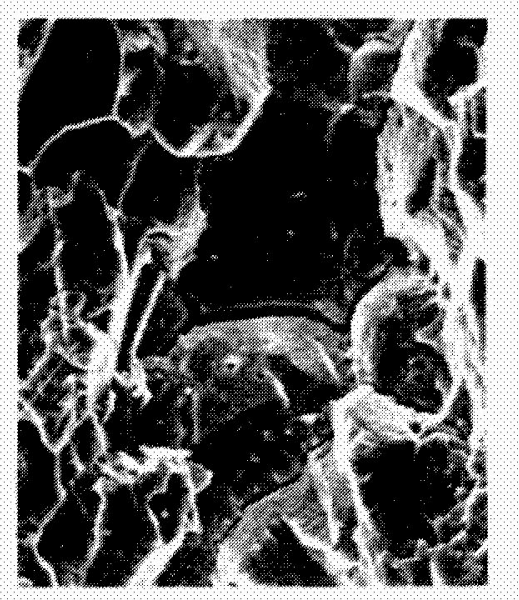

Low 6 an ZR Waspalow

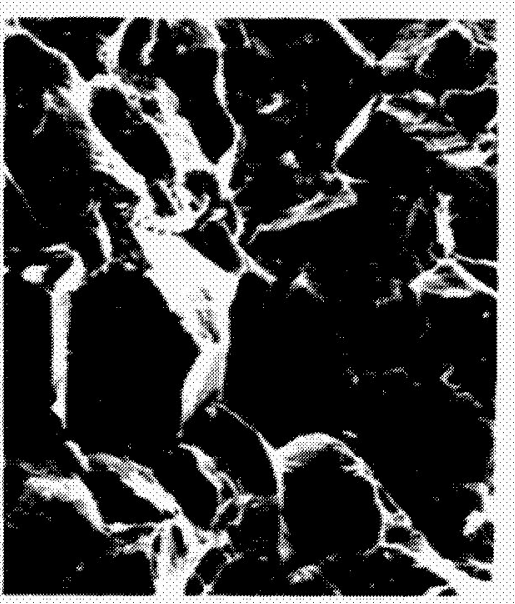

0. $33 \mathrm{~Hz}$ in atr.

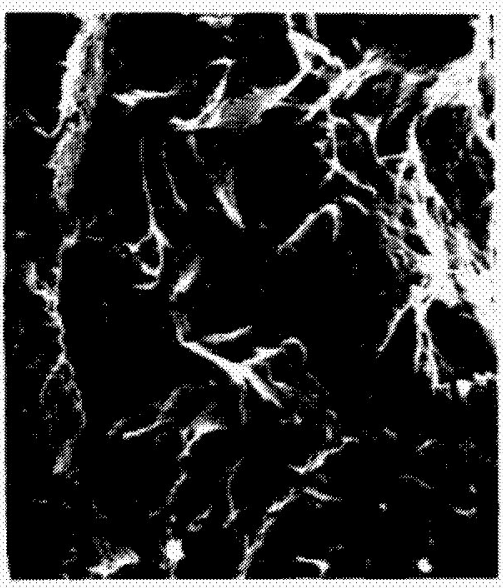

Normal Waspaloy

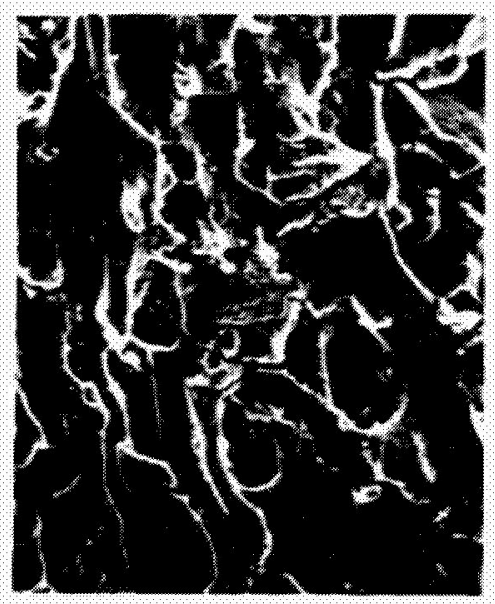

$0.33 \mathrm{~Hz}$ in vacuum,

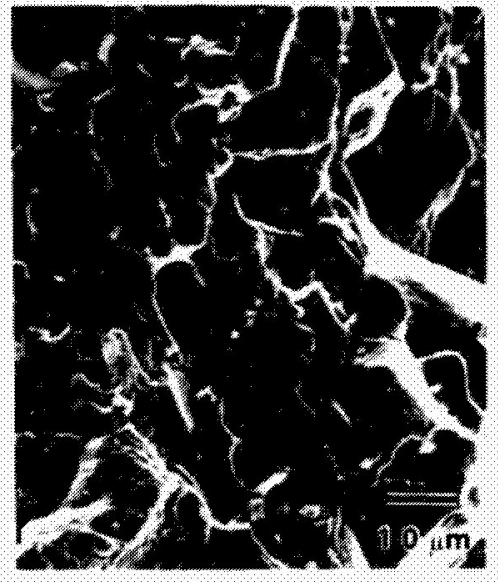

Figure 10. - Fracture modes observed in crack growth tests run at $650^{\circ} \mathrm{C}$ on the two waspaloy compositions. 


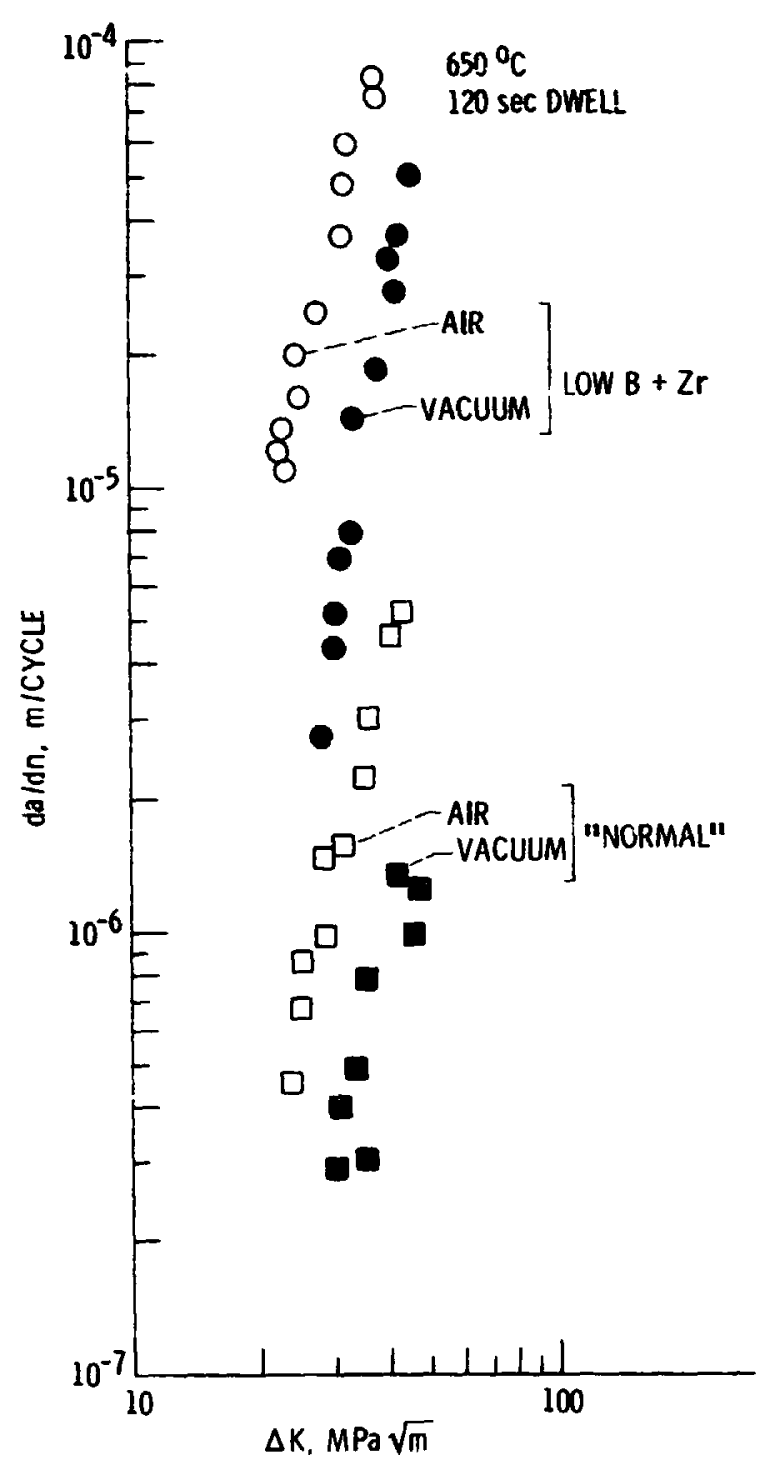

Figure 11. - Fatigue crack growth rates in the 120 second dwell tests run on the two Waspaloy comipositions.

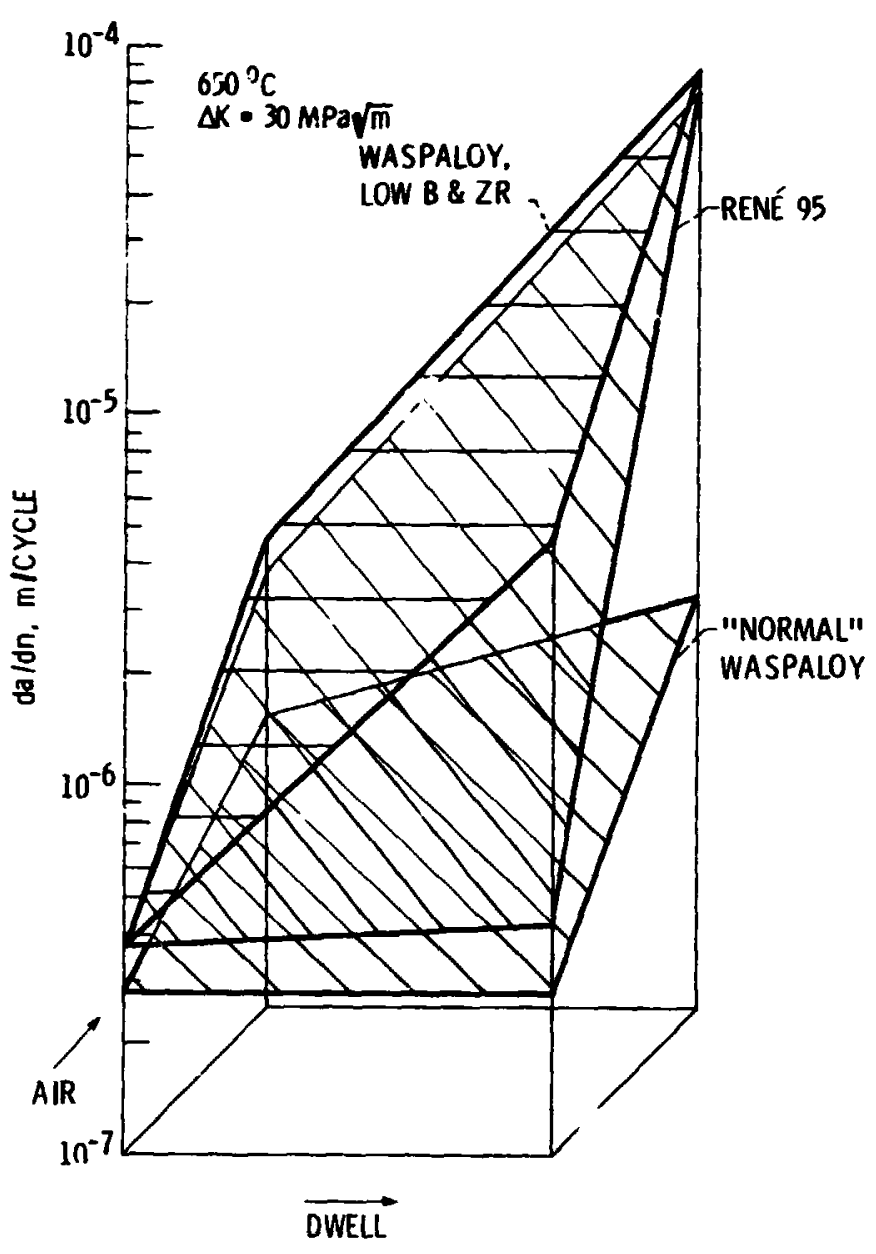

Figure 12 - A comparison of environmental and creep effects on fatigue crack growth behavior of Rene 95 and the two Waspaloy compositions. 


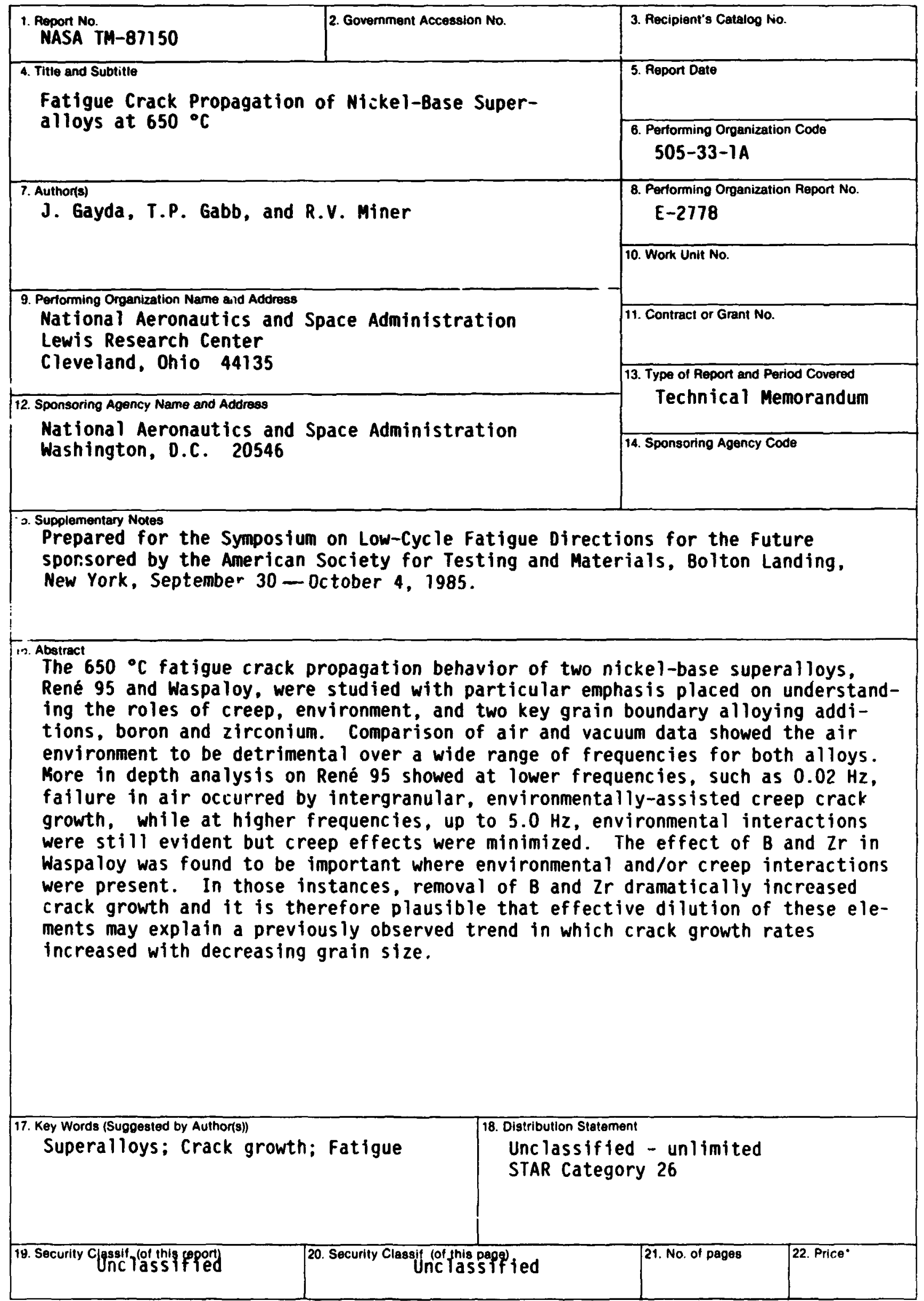

- For sale by the National Technical Information Service, Springfield, Virginia 22161 